\title{
A time course analysis of the affective priming effect
}

\author{
Dirk Hermans \\ University of Leuven, Belgium \\ Jan De Houwer \\ University of Southampton, UK \\ Paul Eelen \\ University of Leuven, Belgium
}

\begin{abstract}
The argument that automatic processes are responsible for affective/evaluative priming effects has been primarily based on studies that have manipulated the stimulus onset asynchrony (SOA; i.e., the interval between the onset of the prime and the onset of the target). Moreover, these SOA studies provide an insight in the time course of the activation processes underlying automatic affect/attitude activation. Based on a fine-grained manipulation of the SOA employing either the evaluative decision task (Experiment 1) and the pronunciation task (Experiment 2) we concluded that affective priming, and hence automatic affect activation, is based on fast-acting automatic processes. The results of Experiment 3 provide a valid explanation for an apparent discrepancy between the results of Experiments 1 and 2 and previous findings. Finally, the results of Experiment 3 support the prediction of Jarvis and Petty (1996) that affective priming effects should be stronger for participants who are more chronically engaged in conscious evaluations.
\end{abstract}

In a series of priming studies (e.g., Bargh, Chaiken, Govender, \& Pratto 1992; Fazio, Sanbonmatsu, Powell, \& Kardes, 1986; Hermans, De Houwer, \& Eelen, 1994) significant priming effects were demonstrated using prime-target pairs for which the affective relation was manipulated. In affective priming studies, positive or negative prime stimuli (words or pictures) are typically presented for 200 milliseconds and are followed by a positive or negative target stimulus after

Correspondence should be addressed to Dirk Hermans, Department of Psychology, University of Leuven, Tiensestraat 102, B-3000 Leuven, Belgium; e-mail: Dirk.Hermans@psy.kuleuven.ac.be

Dirk Hermans is a postdoctoral researcher at the F.W.O. - Flanders.

We wish to express our gratitude to Frank Baeyens, Geert Crombez, An de Decker, Hilde Hendrickx, Peter Silverans, Anneloes Vandenbroucke, and Deb Vansteenwegen for their valuable contributions for this research and/or for their critical comments on an earlier version of this paper. 
an interstimulus interval of 100 milliseconds, resulting in a stimulus onset asynchrony of 300 milliseconds (SOA; i.e., the interval between the onset of the prime and the onset of the target). Results show that the time needed to evaluate the target stimuli as either "positive" or "negative" is significantly shorter when prime and target share the same valence (positive-positive or negativenegative; affectively congruent) as compared to trials on which prime and target are of opposite valence (positive-negative or negative-positive; affectively incongruent).

The generality of this affective priming effect has now been well established by a series of studies. Affective priming effects have been demonstrated for stimuli (attitude objects) as diverse as words (Bargh et al., 1992; Chaiken \& Bargh, 1993; Fazio et al., 1986; Hermans et al., 1994; Klauer, Rossnagel, \& Musch, 1997), nonsense words for which an affective meaning was only recently learned (De Houwer, Hermans, \& Eelen, 1998a), simple line drawings (GinerSorolla, Garcia, \& Bargh, 1994), complex real life colour pictures (Fazio, Jackson, Dunton, \& Williams, 1995; Hermans et al., 1994), and odours (Hermans, Baeyens, \& Eelen, 1998a). Moreover, affective priming effects have been demonstrated using different types of tasks, such as evaluative categorisation (e.g., Bargh et al., 1992; Fazio et al., 1986; Hermans et al., 1994; Klauer et al., 1997), lexical decisions (Hermans, De Houwer, Smeesters, \& Van den Broeck, 1997; Wentura, 1998), and pronunciation (Bargh, Chaiken, Raymond, \& Hymes, 1996; Hermans et al., 1994).

These data have been taken as evidence for the assumption that human subjects are endowed with an evaluative decision mechanism that allows them to automatically evaluate afferent stimulus information (Hermans \& Eelen, 1997; Zajonc, 1980). The idea of automatic stimulus evaluation has been one of the central tenets of several modern cognitive-representational theories of emotion (e.g., Öhman, 1987, 1988; Scherer, 1993), as well as neurophysiological accounts (LeDoux, 1989), and general appraisal models of emotion generation (Lazarus, 1991; Orthony, Clore, \& Collins, 1988). Also, several authors within the field of learning psychology (Martin \& Levey, 1978), social psychology (Bargh, 1996; Zajonc, 1980) and psychophysiology (Cacioppo, Berntson, \& Klein, 1992) have defended the idea of automatic stimulus evaluation.

It is often proposed that the process of automatic stimulus evaluation occurs at a very early stage in information processing, that several stimuli can be evaluated in parallel, and that the basic process is fast, unintentional, efficient, and occurring outside awareness (e.g., Öhman, 1987). In the past, these characteristics have mainly been attributed on the basis of studies that manipulated the SOA level and demonstrated that affective priming effects can be observed at an SOA of $300 \mathrm{~ms}$, but not at a longer SOA of $1000 \mathrm{~ms}$ (De Houwer et al., 1998a, experiment 3; Fazio et al., 1986, experiment 2; Hermans et al., 1994, experiment 1). With reference to the studies of Neely (1977) and Posner and Snyder (1975), it has been argued that the short SOA of $300 \mathrm{~ms}$ is too brief an 
interval to permit participants to develop an active expectancy or conscious response strategies, because such conscious and flexible expectancies would require at least $500 \mathrm{~ms}$ to develop and to influence responses in priming tasks (Fazio et al., 1986). Hence, if presentation of an attitude object prime influences the response time to a target stimulus, despite an SOA as short as $300 \mathrm{~ms}$, it can only be attributed to an automatic, unintentional activation of the corresponding attitude (Bargh et al., 1992, p. 894). Furthermore, it has been argued that if the priming effects observed at SOA $300 \mathrm{~ms}$ were not be based on automatic processes, but are the product of consciously controlled processes, one would expect stronger or at least similar results if participants are provided with more time to process the prime-target relation. This is because controlled processes are generally assumed to be more time-consuming than automatic processes (Hermans, 1996). Indeed, although in the aforementioned studies (De Houwer et al., 1998a; Fazio et al., 1986; Hermans et al., 1994) affective congruency effects were observed at SOA 300, no effects were present at the longer SOA of $1000 \mathrm{~ms}$. This provides an indirect but rather strong indication of the automatic nature of the attitude/affect activation effect.

However, recent conceptions of automatic and controlled processes (for an overview, see Bargh, 1989, 1992, 1996) have fuelled the idea that it is a precarious enterprise to infer process qualities pertaining to intention, efficiency, and awareness on the basis of these SOA studies. Instead, it is a scientifically more appropriate approach to examine each of these characteristics separately. This has been the goal of a series of recent studies, which have demonstrated that affective priming does not depend on an explicit evaluative goal (intention characteristic; Bargh et al., 1996; Hermans et al., 1994), or on the presence of ample processing resources (efficiency characteristic; Hermans, Crombez, \& Eelen, 2000), and can even be observed for subliminally presented primes (awareness characteristic; e.g., Draine \& Greenwald, 1998; Greenwald, Klinger, \& Liu, 1989; Greenwald, Klinger, \& Schuh, 1995; Hermans, 1996). Hence, the general conclusion of this research is that affective priming is based on a (relatively) unconditional process, which is automatic in the sense that it is relatively efficient and can occur independent of an evaluative intention and of awareness of the instigating stimulus.

Although the results of the SOA studies should thus not be viewed as a general indicator of automaticity, they are nevertheless interesting because they provide information about the temporal characteristics of the affective priming effect. Based on the results of the aforementioned experiments in which the SOA was manipulated over two levels (SOA 300 and 1000 ms; De Houwer et al., 1998a; Hermans et al., 1994; Fazio et al., 1986), one could argue that the automatic activation of affect is grounded on a fact-acting process. At SOA $300 \mathrm{~ms}$, the level of activation of the associated evaluation was sufficient to facilitate (inhibit) responding to evaluatively congruent (incongruent) targets. At SOA $1000 \mathrm{~ms}$, however, this activation already seems to have dissipated or its 
influence to be actively suppressed. Presentation of the target at $1000 \mathrm{~ms}$ after presentation of the attitude object appears to have been too late for the prime to facilitate responding to affectively congruent target stimuli.

With the series of three experiments presented here, we wanted to corroborate and extend the results of these SOA studies. In Experiment 1, the SOA was manipulated over five short SOA levels to allow for a more detailed view on the time course of the affective priming effect. Also, in Experiment 1, the relative contribution of facilitation and inhibition effects over the different SOA levels was assessed by comparing response latencies for affectively congruent and incongruent prime-target pairs with appropriate neutral control trials. To test whether the observed priming effects for short SOAs can be generalised to other tasks, in Experiment 2, affective priming at short SOAs was investigated using the pronunciation task (Bargh et al., 1996; Hermans et al., 1994). Experiment 3 was devised to test an explanation for the discrepancy between the results of the present Experiments 1 and 2 and prior SOA studies. Finally, and unrelated to our main focus on the effects of SOA manipulations, in Experiment 3 we assessed whether individual differences in engagement in conscious evaluation (as measured by the Need to Evaluate Scale; Jarvis \& Petty, 1996) would influence the extent of automatic evaluation (as measured by the affective priming procedure).

\section{EXPERIMENT 1}

The studies that have varied the SOA over $300 \mathrm{~ms}$ and $1000 \mathrm{~ms}$ only provide a very partial view on the time course of the affective priming effect. Therefore, in Experiment 1, a fine-grained manipulation of the SOA was used to explore this temporal pattern. Given our hypothesis that affective priming effects, and hence automatic affect activation, are based on a fast-acting process, special attention was devoted to the region of short SOAs. More specifically, in the present study the SOA was varied over five different levels: $-150 \mathrm{~ms}, 0 \mathrm{~ms}, 150 \mathrm{~ms}, 300 \mathrm{~ms}$, and $450 \mathrm{~ms}$.

Similar research has been reported by Klauer and his co-workers (Klauer et al., 1997, experiment 1). Almost simultaneous with, and independent of our research, they varied the SOA with levels of $-100 \mathrm{~ms}, 0 \mathrm{~ms}, 100 \mathrm{~ms}, 200 \mathrm{~ms}$, $600 \mathrm{~ms}$, and $1200 \mathrm{~ms}$, and obtained an affective priming effect for the two shortest non-negative SOAs (SOA $0 \mathrm{~ms}$ and SOA $100 \mathrm{~ms}$ ). However, a crucial difference with the procedure that is typically used in affective priming research is that their proportion of affectively congruent versus affectively congruent trials was 75/25, instead of the standard 50/50 ratio. This uneven proportion has as an important consequence that participants could now use the valence of the prime as a valid predictor of target valence to speed up their evaluative responses. And, although most likely not due to post-lexical or prospective response strategies, this aspect of the procedure indeed has a positive influence 
on the strength of the priming effect (Klauer et al., 1997, experiment 2). Moreover, this influence seems not to be evenly distributed over the different SOA levels, but is confined to short SOAs. Hence, it is not very obvious to generalise the results from their SOA study to the traditional affective priming paradigm. In one of the between-subjects conditions of a second study, Klauer et al. (1997) did employ the standard 50/50 ratio, but only varied the SOA over three levels, being $0 \mathrm{~ms}, 200 \mathrm{~ms}$, and $1200 \mathrm{~ms}$. Here, a priming effect was observed for an SOA of $0 \mathrm{~ms}$, which is a first demonstration for affective priming in a standard (supraliminal) ${ }^{1}$ affective priming study at an SOA shorter than $300 \mathrm{~ms}$.

In the present study, the standard 50/50 ratio of congruent trials was also used, but the SOA was manipulated over five levels which allowed for a more fine-grained time course analysis under standard conditions. Other differences with Klauer et al. (1997, experiment 2) were that we manipulated the SOA on a within-subjects basis, and that apart from the affectively congruent and incongruent trials, now also control trials were included. These consisted of positive or negative targets that were preceded by individually selected neutral prime words. These control trials will allow for an appropriate baseline to assess the influence of facilitation and inhibition processes in affective priming.

\section{Method}

Participants. A total of 49 first year psychology students (17 men, 32 women) participated for partial fulfilment of course requirements.

Materials. Targets were 15 positive and 15 negative adjectives selected from Hermans and De Houwer (1994). Positive and negative targets differed significantly on the affective dimension, $t(28)=46.54, p<.0001 M_{\text {positive }}=$ $\left.6.21 ; M_{\text {negative }}=1.74\right)$, but not for word length, $t(28)=0.22$, n.s. $\left(M_{\text {positive }}=9.0\right.$; $\left.M_{\text {negative }}=8.8\right)$, subjective familiarity, $t(28)=1.79$, n.s. $\left(M_{\text {positive }}=5.14\right.$;

\footnotetext{
${ }^{1}$ In subliminal affective priming studies very short SOAs are common practice. In our own research (Hermans, 1996), for example, we employed SOAs of 70 and $80 \mathrm{~ms}$. Similarly, Draine and Greenwald (1998) employed SOAs as short as $67 \mathrm{~ms}$. An important dissimilarity with the supraliminal studies discussed here is that the short SOAs in these subliminal studies were mainly obtained by reducing the duration of the presentation of the prime (e.g., 17, 33, or $50 \mathrm{~ms}$ in Draine \& Greenwald, 1998), which is obviously done to make primes "subliminal". This procedure stands in marked contrast with the short SOAs in the present studies and the research by Klauer et al. (1997), which were not obtained by reducing the presentation duration of the prime, but in which the actual delay between onset of prime and target was varied while keeping prime duration constant (200 ms). Hence it is difficult to compare the data of these subliminal procedures with the data of the latter studies.
} 
$\left.M_{\text {negative }}=4.57\right)$, or affective extremity, $t(28)=0.53$, n.s. $\left(M_{\text {positive }}=2.21\right.$; $\left.M_{\text {negative }}=2.26\right){ }^{2}$ Primes were 10 positive, 10 negative and 10 neutral nouns, selected on an individual basis from a larger set of 119 Dutch nouns (Hermans, 1996). During prime selection, each word was printed on a separate card $(9 \mathrm{~cm} \times 13 \mathrm{~cm})$. During the priming phase, primes and targets were presented in white upper-case letters ( $8 \mathrm{~mm}$ high, $5 \mathrm{~mm}$ wide) against the black background of an SVGA computer monitor, which was connected to an IBM-compatible 386 computer. A Turbo Pascal 5.0 program operating in SVGA graphics mode controlled presentation of the stimuli. Response times were registered by a voice key that stopped a highly accurate Turbo Pascal timer (Bovens \& Brysbaert, 1990) on registration of a sound.

Procedure. The experiment consisted of three subsequent phases. In the first phase, the prime selection phase, participants were handed over the set of 119 words, and were asked to evaluate them on a 21-category scale $(-100=$ very negative/very unpleasant; $0=$ neutral; $+100=$ very positive/very pleasant). The experimenter stressed that they should rely on their first, spontaneous reaction towards the word. To get an idea about what kinds of words were included in the set, participants took a quick look at the words before starting to rate them.

Following this rating, the participant filled out both parts of the Dutch version of Spielberger's State-Trait Anxiety Inventory (STAI: Spielberger, Gorsuch, Lushene, Vaqy, \& Jacobs, 1983; Dutch version [ZBV], Hermans, 1994; Van der Ploeg, Defares, \& Spielberger, 1980). This questionnaire was only used as a filler task. Meanwhile, out of the participant's sight, the experimenter selected the ten most positively and the ten most negatively rated words, together with 10 neutral control words. These words were then imported as primes into the computer program.

Next, in the actual affective priming phase, participants were told that pairs of words would be presented on the computer screen. They were instructed to attend to the second word and to evaluate it as quickly as possible as either "POSITIVE", or "NEGATIVE", while ignoring the first word (prime), which was only presented to make the task somewhat more difficult. This prime could either precede, follow, or be presented simultaneously with the word they had to evaluate. In order to make it possible for the participant to discriminate prime and target on SOA levels for which there was an overlap in the

\footnotetext{
${ }^{2}$ Affective extremity refers to the (absolute) extent to which the affective rating of a specific word deviates from the mean of the affective rating scale. For example, a word for which the affective score is -2.7 according to the Hermans and De Houwer (1994) norms, has an affective extremity of 1.3 (with ' 4 "' as theoretical mean of these 7-point rating scales).
} 
presentation of both stimuli (see below), the target word was always underscored with a thin white line. Finally, the use of the voice key was explained in detail.

The affective priming phase consisted of 300 experimental trials, subdivided in two series of 150 trials. Within each of both series, there were five blocks of 30 trials for each of the five SOA levels. The presentation order of the five SOA levels was randomised for each participant and for each of the two series of 150 trials separately. In the first half of the priming phase (trials 1-150), each block was preceded by four practice trials, which introduced the SOA that would be used for the following 30 trials. In the second half of the priming phase (trials 151-300), only two practice trials preceded each block.

In each block all 30 primes and 30 targets were presented. For each block, the computer program assigned primes randomly to the targets; the only restriction being that there should be equally large sets of affectively congruent (5 positivepositive, 5 negative-negative), affectively incongruent (5 positive-negative, 5 negative-positive), and control prime-target pairs (5 neutral-positive, 5 neutralnegative). This semi-randomisation was done for each block and each participant separately.

Each trial started with the presentation of a warning tone $(200 \mathrm{~ms} ; 1000 \mathrm{~Hz})$, immediately followed by a $500 \mathrm{~ms}$ presentation of a fixation cross in the centre of the screen. At the offset of the fixation cross, the prime was presented for $200 \mathrm{~ms}$. Depending on the SOA level, the target was presented before, after, or simultaneous with the prime. For the SOA 450 level, the target followed the offset of the prime after an interstimulus interval (ISI) of $250 \mathrm{~ms}$. The ISI was $100 \mathrm{~ms}$ for the SOA 300 level. On trials for which the SOA was $150 \mathrm{~ms}$, the prime was presented alone for $150 \mathrm{~ms}$, followed by a simultaneous presentation of prime and target during $50 \mathrm{~ms}$, after which the prime disappeared. For the SOA 0 level, prime and target appeared simultaneously on the screen, and after $200 \mathrm{~ms}$ the prime disappeared. Finally, for the SOA 150 level, the target was presented first during $150 \mathrm{~ms}$, after which the prime also appeared on the screen for $200 \mathrm{~ms}$.

Due to the overlap in the presentation of prime and target for the SOA $-150 \mathrm{~ms}, 0 \mathrm{~ms}$, and $150 \mathrm{~ms}$ levels, it was chosen to present both stimuli above one another. This presentation mode was used for each of the five SOA levels. Prime and target were vertically separated about $7 \mathrm{~mm}$ from each other (each $3.5 \mathrm{~mm}$ from the centre of the screen). For each trial it was determined randomly whether the prime would be presented below or above the target, thus ensuring locational uncertainty of the target (Glaser \& Glaser, 1989). The target stayed on the screen until the participant gave a response or $2000 \mathrm{~ms}$ elapsed. When the participant had given a correct response, the experimenter entered a code. In case of an incorrect response or in case of a voice key failure a different code was entered. The intertrial interval was always $4 \mathrm{~s}$. 


\section{Results}

The data from trials on which a voice key failure occurred or on which an incorrect response was given were excluded from the analysis $(5.1 \%)$, together with all response latencies shorter than $250 \mathrm{~ms}$ or longer than $1500 \mathrm{~ms}(3.87 \%)$. The analyses are based on the remaining data (91.03\% of all observations).

A priori contrasts were calculated between response latencies for affectively congruent, control, and affectively incongruent trials for each of the SOA levels separately. For the SOA 450 level, there was no difference between affectively congruent and affectively incongruent trials $(F=2.88$; n.s. $)$. Also, none of the comparisons with the control trials was significant, $M_{\text {congruent }}=719, M_{\text {control }}=$ 731, $M_{\text {incongruent }}=734$ (congruent-control: $F=1.91$, n.s. incongruent-control: $F<1$ ). Similarly, for the SOA 300 level, the crucial contrast between affectively congruent and incongruent trials failed to reach the conventional level of significance $\left(F<1 ; M_{\text {congruent }}=719, M_{\text {incongruent }}=728\right)$. Again also none of the comparisons with the control trials $\left(M_{\text {control }}=716\right)$ was significant $(F \mathrm{~s}<1.21)$. For the SOA 150 level, however, there was a clear influence of the affective relation between prime and target. Affectively congruent trials led to significantly shorter response latencies than affectively incongruent trials, $F(1,48)=13.30 ; p<.001, M_{\text {congruent }}=694, M_{\text {incongruent }}=724$. With respect to the control trials $(M=710)$ the difference with affectively congruent trials reached significance, $F(1,48)=3.44 ; p<.05$, whereas the difference with incongruent trials was only marginally significant, $F(1,48)=2.26 ; p=.07$. A similar pattern of results was obtained for the SOA 0 level. Here, affectively congruent trials again led to significantly shorter response latencies than affectively incongruent trials, $F(1,48)=7.15 ; p<.05, M_{\text {congruent }}=818, M_{\text {incongruent }}=846$. Control pairs also produced faster response latencies $(M=813)$ than incongruent pairs, $F(1,48)=7.49 ; p<.05$, but did not differ from congruent pairs, $F<1$. Finally, for the SOA -150 level, none of the comparisons between congruent, control and incongruent prime-target pairs reached significance $\left(M_{\text {congruent }}=648, M_{\text {control }}=\right.$ $\left.642, M_{\text {incongruent }}=642\right)($ for all three comparisons: $F<1)$.

\section{Discussion}

The results show a clear influence of the SOA manipulation. ${ }^{3}$ Only for the two shortest, non-negative SOA levels (0 and $150 \mathrm{~ms})$ did we observe a significant effect of affective congruence. This is in line with the idea that the affective priming effect, and hence automatic affect activation, is based on fast-acting

\footnotetext{
${ }^{3}$ In fact, an additional analysis of variance with block (trials 1-150/trials 151-300), SOA ( -150 / $0 / 150 / 300 / 450$ ), target valence (positive/negative), and affective congruence (congruent/incongruent) as within-subjects variables, revealed a main effect of affective congruence, $F(2,96)=6.26 ; p<.005$ $\left(M_{\text {congruent }}=720, M_{\text {control }}=723, M_{\text {incongruent }}=736\right)$, which was mediated in a significant $\mathrm{SOA} \times$ Affective Congruence interaction, $F(8,384)=2.11 ; p<.05$.
} 
cognitive processes. Although facilitation effects at negative SOAs have been observed in other paradigms (e.g., Kiger \& Glass, 1983), no priming effect was found in our study at SOA -150 . Most probably, the valence of the prime was not yet fully processed at the moment the participant evaluated the target. Also, when the SOA was prolonged to 300 or $450 \mathrm{~ms}$, significant priming effects were no longer observed. Although this is in line with the idea that affective priming is grounded on quick activation processes that swiftly dissipate, it is still surprising that no significant difference between affectively congruent and affectively incongruent trials was demonstrated at SOA 300. After all, significant priming effects are a standard observation at this SOA level (e.g., Fazio et al., 1986). Nevertheless, in the study by Klauer et al. (1997, experiment 2) there was a similar absence of priming effects at SOA 200 given a significant effect on SOA 0. For the time being we have no valid explanation for this discrepancy, and postpone this discussion until a later moment.

With respect to the proportion of facilitation and inhibition in affective priming, we have to conclude that whereas the congruence effect at SOA 0 is entirely based on inhibition for affectively incongruent trials, facilitation processes seem to have played a more important role in the priming effect at SOA 150. These findings are in line with the results of previous studies which also showed that affective priming effects are due to both facilitation and inhibition (Hermans et al., 1994, experiment 1; Hermans et al., 2000). Although conclusions about the influence of facilitation and inhibition effects are dependent on the appropriateness of the control condition, there are good reasons for assuming that the individually selected neutral prime words that were used as controls in the present experiment provide a suitable basis to assess facilitation and inhibition effects. Hence, theories about the mechanisms that are responsible for the affective priming effect should not only account for inhibition effects, but also for the facilitation effects observed in this and other studies. It would, however, be premature to conclude on the basis of the present findings that these inhibition and facilitation effects would show a different time course.

\section{Experiment 2}

To investigate whether the findings of Experiment 1 can be generalised to other response tasks, we originally conducted an exact replication of Experiment 1, but now employing the pronunciation task (Bargh et al., 1996; Hermans et al., 1994). However, in this study (Hermans, 1996, experiment 8), we failed to obtain significant priming effects at each of the five SOA levels. An important aspect of the results was however that the mean response latency in this pronunciation experiment was very short $(M=376)$ as compared to previous affective priming studies which employed the pronunciation task (respectively, 518, 522, and $500 \mathrm{~ms}$ for the three studies reported by Bargh et al., 1996; $450 \mathrm{~ms}$ in the study reported by Hermans et al., 1994), and as compared to pronunciation 
studies in general (e.g., Balota \& Lorch, 1986, who observed a mean reaction time of $540 \mathrm{~ms}$ ). One could argue that due to the repeated pronunciation (10 times) of the same set of 30 target words by the participants, the reading/ pronunciation process by itself had become so automated that other automatic processes could no longer exert an influence on the speed at which these words were pronounced. Facilitation effects might have simply not shown up because of a floor effect in the response latencies.

For this reason, in the present study, we reduced the number of times the target words had to be pronounced, by reducing the number of (within subjects) SOA levels to three. Also, control primes were no longer used. These changes drastically reduced the number of trials from a total of 300 to 120 . The SOAs used in this study were SOA 150, SOA 300, and SOA 1000. The latter SOA was chosen, because until present a discrepancy in priming effects for short and long SOAs, as has repeatedly been demonstrated for the evaluative decision task, has not been investigated in the pronunciation task.

Apart from using the pronunciation task, the reduction of SOA levels, and the omission of control trials, a final difference with Experiment 1 was that primes were no longer selected on an individual basis. In line with previous pronunciation studies, a fixed set of normatively selected primes was now used.

\section{Method}

Participants. A total of 32 second year psychology students (8 men, 24 women) participated for partial fulfilment of course requirements.

Materials. The selection of primes and targets were based on Hermans and De Houwer (1994). On the basis of their affective and familiarity ratings, 10 positive and 10 negative nouns were selected as primes. They differed significantly for the affective dimension, $t(18)=20.19, p<.001\left(M_{\text {positive }}=6.04\right.$; $\left.M_{\text {negative }}=2.01\right)$, but not pertaining to word length, $t(18)=0.00$, n.s. $\left(M_{\text {positive }}=\right.$ $\left.5.5 ; M_{\text {negative }}=5.5\right)$, subjective familiarity, $t(18)<1$, n.s. $\left(M_{\text {positive }}=5.17\right.$; $\left.M_{\text {negative }}=5.10\right)$, or affective extremity, $t(18)=0.25$, n.s. $\left(M_{\text {positive }}=2.04\right.$; $M_{\text {negative }}=1.99$ ).

Targets were 10 positive and 10 negative adjectives, which differed significantly for the affective dimension, $t(18)=32.45, p<.001\left(M_{\text {positive }}=6.04\right.$; $\left.M_{\text {negative }}=1.84\right)$, but not pertaining to word length, $t(18)=0.31$, n.s. $\left(M_{\text {positive }}=\right.$ $\left.6.7 ; M_{\text {negative }}=7\right)$, subjective familiarity, $t(18)=0.473$, n.s. $\left(M_{\text {positive }}=6.00\right.$; $\left.M_{\text {negative }}=5.88\right)$, or affective extremity, $t(18)=1.01$, n.s. $\left(M_{\text {positive }}=2.04\right.$; $M_{\text {negative }}=2.17$ ). The apparatus and software were the same as in Experiment 1.

Procedure. The experiment was introduced as a study on word recognition and the speed at which people are able to read words. Because we now used a fixed set of primes, there was no prime selection phase. Instructions for the 
priming phase were similar to those of Experiment 1, with the exception that no more reference was made to (the importance of) the valence of the stimuli, and that participants were now asked to pronounce the target words.

The experiment consisted of 120 trials, subdivided in two series of 60 trials. Within each of both series, there were three blocks of 20 trials for each of the three SOA levels. The presentation order of these three levels was randomised for each participant, and for each of the two series of 60 trials separately. In the first half of the experiment, four practice trials preceded each block; in the second series of trials, there were only two practice trials for each block.

In each block all 20 primes and targets were presented. The computer program assigned primes randomly to the targets; the only restriction being that there should be equally large sets of affectively congruent ( 5 positive-positive, 5 negative-negative) and affectively incongruent ( 5 positive-negative, 5 negativepositive) prime-target pairs. This semi-randomisation was done for each block and each participant separately.

Primes were always presented for $200 \mathrm{~ms}$. For the SOA 300 and the SOA 1000 levels, the interval between the offset of the prime and the onset of the target was $100 \mathrm{~ms}$ and $800 \mathrm{~ms}$, respectively. For trials with SOA 150, the target appeared $150 \mathrm{~ms}$ after the onset of the prime. The intertrial interval was always $2 \mathrm{~s}$. All other presentation parameters were the same as in Experiment 1, including locational uncertainty at all SOA levels.

\section{Results}

The data from trials on which a voice key failure occurred or an incorrect response was given were excluded from the analysis (3.25\%), together with all response latencies shorter than $150 \mathrm{~ms}^{4}$ or longer than $1500 \mathrm{~ms}(1.75 \%)$. The analyses are based on the remaining data (95\% of all observations).

As in the previous experiment, a priori contrasts were calculated between congruent and incongruent trials for each of the three levels of the SOA variable. As was predicted, for the SOA 1000 level, the difference between affectively congruent and incongruent prime-target pairs proved not to be significant, $F(1,31)<1, M_{\text {congruent }}=413, M_{\text {incongruent }}=414$. Also, for the SOA 300 level there was no difference between affectively congruent and incongruent trials, $F(1,31)<1, M_{\text {congruent }}=413, M_{\text {incongruent }}=414$. At the SOA 150 level however, there was a clear effect of affective congruence in the predicted direction, $F(1,31)=7.21, M_{\text {congruent }}=451, M_{\text {incongruent }}=465$.

\footnotetext{
${ }^{4}$ In line with previous research (Hermans, 1996), the limits for outliers were set at 150 and $1500 \mathrm{~ms}$ instead of 250 and $1500 \mathrm{~ms}$, because mean response latencies for the pronunciation task are significantly shorter as compared to the evaluative decision task.
} 


\section{Discussion}

The present results replicate the finding of Experiment 1 that affective priming effects are present at short (SOA 150), but not at longer SOAs (SOA 300, SOA 1000). Also, the priming effect at SOA 150 provides a strong indication for the idea that automatic affect activation is based on processes that are not goaldependent (Bargh, 1989). In Experiment 2, participants were no longer asked to make conscious evaluations during a prime selection phase or during the priming phase, and no reference was made to the importance of the valence of the stimuli. Therefore, it seems plausible to conclude that an evaluative processing goal (intention characteristic of automaticity) is not a necessary precondition for the automatic affect activation effect to occur.

Although the absence of a priming effect at SOA 1000 and the presence of an effect at SOA 150 confirmed our expectations, the absence of a priming effect at SOA 300 was not predicted given previous results (Bargh et al., 1996; Hermans et al., 1994). One possible explanation relates to the general speed at which target words were pronounced, as was discussed in the introduction to this study. The reduction of the number of times participants had to pronounce the target stimuli indeed seemed to have an effect on the mean pronunciation latency, which was $428 \mathrm{~ms}$ in this study, as compared to a mean of $376 \mathrm{~ms}$ in the study discussed earlier (Hermans, 1996, experiment 8). Nevertheless, there were marked differences in response latencies between the three SOA levels of the present study. An additional ANOVA with SOA level and congruence as within-subjects variables indeed showed a significant main effect of SOA level, $F(2,62)=20.21$; $p<.0001$. Response latencies for the SOA 150 condition $(M=458)$ were significantly longer than response latencies for SOA $300(M=414)$ and SOA $1000(M=414)$, which did not differ (Tukey HSD a posteriori contrasts). This difference is probably a result of the fact that prime and target are presented simultaneously for some time at SOA 150, which might have been somewhat confusing for the participants. It is possible that the absence of a priming effect at SOA 300 is (partly) due to the relatively short pronunciation latencies, which might again created a floor effect, whereas the longer reaction times at SOA 150 left more room for other processes to have an impact. Without going into the theoretical reasoning behind these observations, we want to point out that a similar positive relation between mean pronunciation latencies and the strength of the priming effect has been described by Williams (1996) for semantic priming tasks. Confirming this idea, we observed significant affective priming in a pronunciation study when responses were retarded by degradation of the target stimulus, but not when targets were undegraded (Hermans et al., 1997). Nevertheless, longer response latencies are not a sufficient precondition to observe affective priming effects in the pronunciation task. Klauer and Musch (1998) for example, obtained similar mean pronunciation latencies as Bargh et al. (1996), but failed to find an effect in a series of experiments. 
Another explanation for the absence of priming effects at SOA 300 in Experiments 1 and 2 might however be related to a specific presentation parameter used in these studies. This possibility was investigated in Experiment 3.

\section{EXPERIMENT 3}

As discussed before, the absence of affective priming effects at SOA 300 in Experiments 1 and 2 was surprising given the results of previous studies. An important difference between Experiments 1 and 2 and these previous studies on affective priming, however, is that whereas primes and targets are usually presented both on exactly the same place in the centre of the screen, they were now presented one above another, with a distance of approximately $7 \mathrm{~mm}$ from each other (each $3.5 \mathrm{~mm}$ from the centre of the screen). This physical separation in the presentation of both stimuli was necessary because of the overlap in the presentation of prime and target at the SOA $-150 \mathrm{~ms}, 0 \mathrm{~ms}$, and $150 \mathrm{~ms}$ levels. Although locational uncertainty was obtained by changing the position of both stimuli on a random basis, it is however possible that this procedural aspect had a negative influence on the priming effect at SOA 300. Activation effects are indeed known to be sensitive to parametric variables such as the visual angle of presentation (e.g., Holender, 1986). It could be that this parameter has a more detrimental influence on the affective priming effect at SOA 300 than at SOA 150 or SOA 0 , if one assumes that SOA 300 is already at the end of the activation curve and priming effects are hence smaller at this level anyway. An indication for the idea that SOA 300 is situated at the edge of the activation curve stems from a series of three studies in which we were unable to replicate the standard affective priming effect in the evaluation task at an SOA of $300 \mathrm{~ms}$, whereas a reduction of the SOA to $150 \mathrm{~ms}$ was sufficient for the priming effects to re-emerge in three subsequent studies, all other parameters being equal (Hermans, 1996, experiments 10-15). Also, Greenwald et al. (1995) failed to find priming effects with unmasked primes at SOAs ranging between 250 and $300 \mathrm{~ms}$.

To test the hypothesis that the way in which primes and targets were presented in Experiments 1 and 2 had a detrimental influence on the priming effects at SOA 300, the presentation modus was manipulated in the present experiment. On half of the trials, primes and targets were presented in the traditional way (centred condition; i.e., in the centre of the screen), while on the other half, prime and target were presented one above another as was done in Experiments 1 and 2 (uncentred condition). As in Experiment 1, the evaluative decision task was employed.

In addition, but unrelated to the previous issue, we wanted to investigate the potential influence on the affective priming effect of inter-individual differences pertaining to a chronic tendency to engage in evaluative responding, also referred to as the need to evaluate (Jarvis \& Petty, 1996). Although evaluation is 
a pervasive and dominant response in judgement for most people across the many situations and objects they encounter, Jarvis and Petty (1996) argued that some people are consistently more prone to engage in evaluation than others. Evidence for this claim was obtained in a series of studies, which were mainly based on the 16-item Need to Evaluate Scale which was specially construed for the purpose of this research, and which has high internal consistency, a single factor structure, high test-retest reliability, and convergent and discriminant validity (Jarvis \& Petty, 1996). Based on their findings, these authors proposed some implications for future research. One of them directly touches the issue of automatic attitude/affect activation and affective priming: "Similarly, it would be interesting to examine whether the need to evaluate moderates the likelihood and extent of the automatic attitude activation effect (e.g., Fazio et al., 1986)', (Jarvis \& Petty, 1996, p. 191). To test this hypothesis, two groups of students were invited for the present experiment. One group obtained high scores on the NES (high need to evaluate), while the other group scored low (low need to evaluate). According to their suggestion, a stronger affective priming effect was expected for the high NES group as compared to the low NES group.

\section{Method}

Participants. $\quad$ During the first month of the academic year a group of 384 students filled out the Dutch version (Hermans, 1997) of the Need to Evaluate Scale (NES; Jarvis \& Petty, 1996) among five other questionnaires. The mean score for the NES was 52.78 ( $\mathrm{SD}=10.31$ ), with scores ranging from 27 to 77 . Based on their individual score on the NES, 25 students with the highest score, and 25 students with lowest score were invited to participate in this and/or another study (which was unrelated to the present research questions). For the present study, a total of 25 students volunteered to participate. The data of two participants were discarded because of technical problems, together with a third student for whom Dutch was not the mother tongue, and who did not understand all the words. The final sample consisted of 11 participants with a low score on the NES (5 men, 6 women), and 11 participants with a high score on the NES (1 man, 10 women).

Materials. The stimulus material and the presentation characteristics were exactly the same as in Experiment 2. The experiment was run on an IBMcompatible Pentium computer.

Procedure. The instructions concerning the evaluative decision task were the same as in Experiment 1. The experiment consisted of 80 experimental trials, subdivided in two series of 40 trials. Each of both series contained one block of 20 trials in which prime and target were presented in the centre of the screen (SOA 300 centred), and one block of 20 trials in which prime and target 
appeared one above another (SOA 300 uncentred). The order of those two presentation modes (centred vs. uncentred) was determined at random for each series of two blocks, and each participant separately. The presentation parameters and the way in which congruent and incongruent prime-target pairs were construed were the same as for the SOA 300 condition of Experiments 2, with the exception that for the centred condition, the prime and target were both presented on the same location in the centre of the screen.

After the priming phase, the participants were asked whether they had any idea about on the basis of what questionnaire they were invited to participate. None of the participants, however, had any idea. Next, they were asked to fill out the NES for a second time, and finally they were debriefed about the purpose of the study and the selection criteria that were used.

\section{Results}

Questionnaire data. There was a clear significant difference between the high and the low NES groups for the first administration of the NES, on the basis of which they had been selected, and which took place six months before the actual priming experiment, $t(20)=38.79, p<.0001$. The low NES group had a mean score of 33.1 (ranging from 29 to 36), whereas the high NES group had a mean score of 71.2 (ranging from 69 to 75). Although somewhat less strong, there remained a highly significant difference between both groups at the time of testing, $t(20)=13.83, p<.0001$. The low NES group had a mean score of 36.7 (ranging from 30 to 45 ), whereas the high NES group had a mean score of 65.3 (ranging from 57 to 74 ).

Response latency data. The data from trials on which a voice key failure occurred or on which an incorrect response was given were excluded from the analyses (2.84\%). In addition, all response latencies shorter than $250 \mathrm{~ms}$ or longer than $1500 \mathrm{~ms}$ were excluded to reduce the influence of outlier responses $(1.14 \%)$. The analyses are based on the remaining data $(96.02 \%$ of all observations).

Conform the results of Experiments 1 and 2, the difference between affectively congruent and affectively incongruent trials was not significant for the uncentred condition, where primes and targets were presented one above another, $F(1,20)<1$, n.s., $M_{\text {congruent }}=596, M_{\text {incongruent }}=599$. For the centred conditioned there was, however, a significant difference between congruent and incongruent trials in the predicted direction, $F(1,20)=3.52, p<.05, M_{\text {congruent }}=$ $562, M_{\text {incongruent }}=578$, thus replicating earlier findings (e.g., Bargh et al., 1992; Fazio et al., 1986).

To investigate the impact of our between-subjects manipulation, an additional analysis of variance was carried out, with group (low NES/high NES) as a between-subjects variable, and block (trials 1-40/trials 41-80), presentation 
modus (centred/uncentred), target valence (positive/negative), and affective congruence (congruent/incongruent) as within-subjects variables. As predicted by Jarvis and Petty (1996), a significant interaction between group and affective congruence emerged, $F(1,20)=4.37, p<.05$. Subsequent a priori contrasts showed that the low-NES group did not respond differently to affectively congruent as compared to affectively incongruent trials, $F(1,20)<1$, n.s., $M_{\text {congruent }}$ $=584, M_{\text {incongruent }}=579$. For the high-NES group on the other hand, this difference was statistically significant, $F(1,20)=5.94, p<.05, M_{\text {congruent }}=574$, $M_{\text {incongruent }}=598$.

\section{Discussion}

The results of Experiment 3 lead to two major conclusions. The first is that the absence of the priming effect in the SOA 300 condition of Experiments 1 and 2 is at least partly due to the specific way of presenting prime and target one above another. The fact that this presentation mode had a more detrimental effect on this SOA level than on the shorter SOAs (SOA 150 and SOA 0) is probably due to the fact that SOA 300 is already at the end of the activation curve. Hence, it might be that the priming effects are somewhat underestimated for all of the SOA levels in Experiments 1 and 2 (including SOA 450). Given the presentation overlap at SOAs such as SOA 0 or SOA 150, it is physically impossible to present both prime and target at the same location. But it would be interesting to investigate priming effects at what we expect to be the end of the activation curve of affective priming effects (e.g., SOA 200, SOA 300, SOA 400) using the traditional "centred" presentation mode.

Second, a significantly stronger affective priming effect was observed for the high-NES group as compared to the low-NES group. This finding is in line with the proposal of Jarvis and Petty that even though most people might evaluate objects to which they are frequently exposed to an extent that is sufficient to produce automatic activation of that evaluation in memory, the extent of such responding could still reliably vary between individuals (Jarvis \& Petty, 1996, p. 173). This difference is attributed to the fact that some people might initially evaluate an object and then seldom if ever engage in evaluation of that object again, whereas, in contrast, other people could retrieve and update their evaluation on a regular basis.

Such an account is reminiscent of a study of Fazio and his co-workers (Fazio et al., 1986, experiment 3) in which participants were asked to consciously evaluate a series of positive and negative words for five times, and for another set of words they had to decide whether or not the word was a one-syllable word. This manipulation had a significant effect on the results of the subsequent affective priming task in which these words were used as primes. For primes that had been repeatedly evaluated prior to the priming phase, the affective priming effect was stronger than for primes for which a nonevaluative decision was 
asked. This result is easily explained if one assumes that repeated conscious evaluation of an attitude object strengthens the object-evaluation association (Powell \& Fazio, 1984), which in turn might facilitate automatic attitude activation.

Similarly, participants that score high on the NES, might possess stronger object-evaluation associations due to their chronic engagement in evaluative responding. It remains, however, somewhat surprising that no affective priming effect at all was observed for the low-NES group, in particular because the primes that were used in Experiment 3 were not unfamiliar, and were rather extremely valenced. Future studies should further examine the role of these individual differences in evaluative responding on affective priming for moderately valenced versus more extremely valenced stimuli.

\section{GENERAL DISCUSSION}

The affective priming procedure has become an important tool in the research on automatic evaluative processing. Recent studies that have employed this paradigm have not only demonstrated that automatic stimulus evaluation is a rather general phenomenon which can be generalised to different types of stimuli, but have also established that this automatic activation of evaluations/attitudes is based on processes which are efficient, and can occur independent of an evaluative intention and awareness of the activating stimulus.

The results of the present series of experiments do not only corroborate the conclusions of previous studies which have varied the SOA over two levels (SOA 300 and SOA 1000), but also provide a more detailed analysis of the temporal course of the affective priming effect. Based on the results of Experiments 1 and 2, we can conclude that the activation curve of affective priming has a rather quick onset (SOA 0), with a maximum around SOA 150 after which the effect rather quickly dissipates. Most probably, as is pointed out by the results of Experiment 3, an SOA of $300 \mathrm{~ms}$ is already located at the edge of the activation curve. Hence, we can conclude that affective priming shows the signature of fast-acting cognitive processes. At present, it is however still unclear to what extent the decrease in the affective priming effect at larger SOAs is due to a simple diminution of the level of activation, an active process of inhibition, or a combination of both. Together with a more detailed examination of the relative contribution of facilitation and inhibition processes over different SOA levels, the study of the processes involved in the decline of affective priming at longer SOAs, can be regarded as an important future research topic.

The data not only confirm that affective priming effects can be found at very short SOAs using the evaluative decision task (see also Klauer et al., 1997, experiment 2), but the results of Experiment 2 show that this observation can also be generalised to the pronunciation task. 
Apart from the fact that the present results provide an insight in the temporal course of affect activation, they are quite consequential with respect to the discussion on the nature of the processes that are responsible for the affective priming effect (see De Houwer, Hermans, Rothermund, \& Wentura, 1998b; Hermans, Van den Broeck, \& Eelen, 1998b; Klauer, 1998). Based on results with a negative priming variant of the affective priming paradigm, Wentura (1999), for example, has proposed a model for affective priming that is mainly based on response path interference processes. The facilitation effect in the SOA 150 condition is however a strong indication that there is more to affective priming than only such inhibitory processes. Similar facilitation effects were also observed in other studies (Hermans et al., 1994, experiment 1; Hermans et al., 2000). Using individually selected neutral stimuli as control primes, conform the present Experiment 1, Hermans et al. (1994, experiment 1) demonstrated both significant facilitation for affectively congruent trials and significant inhibition for affectively incongruent trials in a picture-picture paradigm (see Hermans, 1996 for the analyses concerning facilitation and inhibition). Because these neutral control primes were selected on an individual basis from the same pool of stimuli as the positive and negative primes, and because we have no reason to believe that these neutral stimuli differed from the negative and positive primes apart from their affective valence, they can be regarded as an appropriate basis to assess facilitation and inhibition effects. This in contrast to other studies (e.g., Fazio et al., 1986) which have employed letter-strings as neutral control primes (e.g., BBB), which not only differ on the evaluative dimension, but also with respect to the "wordness" variable. A third strategy for the selection of control primes was adopted in Hermans et al. (2000), who selected prime words on the basis of normative ratings (Hermans \& De Houwer, 1994). In this study, neutral control primes only differed with respect to their affective meaning, but not with respect to word length or word familiarity. Nevertheless, again significant facilitation as well as inhibition was observed in the error data, whereas in the response latency data the affective priming effect was only due to facilitation. Taken together, these data strongly suggest that models of affective priming should not only deal with inhibition for affectively incongruent trials, but also have to explain the observed facilitation effects.

With respect to such models of affective priming, De Houwer et al. (1998b) discussed three possible loci of the affective priming effect, which they called the subordinate, superordinate, and response account, respectively. The subordinate account goes back to the original model of Fazio et al. (1986), who proposed a model of affective priming that is similar to the semantic network account of associative priming. Assuming that all concepts with the same valence are linked in semantic memory, activation of the prime concept will spread to concepts with the same valence. As a result, affectively congruent concepts will have a higher activation level than affectively incongruent concepts. Hence, it will take less time for the activation level of the target concept to 
reach a threshold level that is necessary for identification and subsequent affective categorisation in case of affectively congruent pairs as compared to incongruent prime-target pairs. The essence of the subordinate model is that primes are assumed to facilitate the identification of affectively congruent targets by the pre-activation of subordinate semantic representations of the latter.

Besides priming at a subordinate level, a prime could pre-activate the superordinate semantic representation that corresponds to its valence (i.e., positive or negative). When a prime and target have the same valence, they will activate the same superordinate node. When the valence of the prime and target differ, however, different superordinate nodes will be activated and it will take time in order to solve the conflict. According to this superordinate account, primes bias the decision regarding the valence of the target rather than the decision regarding the identity of the target (as is assumed in subordinate models of affective priming). Besides priming at a super- or subordinate level, De Houwer et al. (1998b) argue that affective priming could also be due to processing at the response level. Assume that participants have to name the valence of the targets by saying 'POSITIVE', or "NEGATIVE'. In this situation, there are two output nodes representing lexical, phonological, and/or motor information about the two possible responses. After identification of the target, and after the valence of the target has been determined, the correct response node can be activated. One can assume, however, that the prime is also (automatically) processed at these stages and can thus also activate the response node that corresponds to its valence. If this is the case, the response node activated by an incongruent prime will differ from that activated by the target, thus resulting in a response conflict that does not arise when prime and target are affectively congruent. Affective priming is thus attributed to the fact that primes influence a decision regarding the identity of the correct response (De Houwer et al., 1998b). Although the three accounts are explained here with reference to traditional semantic network models, the classification is actually independent of the type of processing model one uses, and can hence easily be translated to, for instance, connectionist models (De Houwer et al., 1998b).

Within the discussion concerning the relative importance of each of these types of processes (De Houwer et al., 1998b; Hermans et al., 1998a; Klauer, 1998), an important role is attributed to the results of a limited series of experiments in which affective priming was demonstrated using a pronunciation task in stead of an evaluation task (e.g., Bargh et al., 1996, experiments 1-3; Hermans et al., 1994, 1997; see also Experiment 2). This is because the results of these pronunciation studies provide relatively strong evidence for the subordinate account, and cannot easily be explained in terms of superordinate or response accounts. For this reason, the pronunciation studies have gained a lot of interest, and it is in this context that the data of Experiment 2 gain additional importance, as they provide extra support for the idea that subordinate processes play a significant role in the production of affective priming effects. 
Nevertheless, a number of studies have failed to replicate the affective priming effects in the pronunciation task. As we already noted in the introduction to Experiment 2, we failed to find significant priming effects in a conceptual replication of Experiment 1 using the pronunciation task (Hermans, 1996, experiment 8). Also, Klauer and Musch (1998) failed to replicate the effect in five consecutive experiments, despite using accurate procedures and ensuring sufficient statistical power. Other failures to replicate have been reported by De Houwer et al. (1998a, experiment 2), and Klauer, Rossnagel, and Musch (1995). Hence, doubts have been raised about the robustness of affective priming effects in a pronunciation task. And to make the picture even more complex, Glaser and Banaji (1999) even demonstrated reverse priming effects in a series of five pronunciation studies (i.e., faster responses for incongruent trials as compared to congruent trials).

At the moment, however, we are starting to grasp some of the variables that might be important to understand this complex picture of affective priming results using the pronunciation task (De Houwer \& Hermans, 1999; Hermans et al., 1997). And because of its theoretical value with respect to the understanding of the mechanisms behind affective priming, it is our conviction that the study of affective priming effects using the pronunciation task is a line of research that is certainly worth pursuing in the very near future.

Similarly, the results concerning the NES in Experiment 3 open the perspective of a new line of research concerning inter-individual differences in automatic evaluative responding. It will not only be of importance to investigate whether the presently observed interaction between NES and affective congruence can be replicated, but future studies should further examine the role of these individual differences in evaluative responding on affective priming for moderately valenced versus more extremely valenced stimuli.

Manuscript received 3 May 1999

Revised manuscript received 7 November 1999

\section{REFERENCES}

Balota, D., \& Lorch, R.F. (1986). Depth of automatic spreading activation: Mediated priming effects in pronunciation but not in lexical decisions. Journal of Experimental Psychology: Learning, Memory, and Cognition, 12, 336-345.

Bargh, J.A. (1989). Conditional automaticity: Varieties of automatic influence in social perception and cognition. In J.S. Uleman \& J.A. Bargh (Eds.), Unintended thought (pp. 3-51). New York: Guilford Press.

Bargh, J.A. (1992). The ecology of automaticity: Toward establishing the conditions needed to produce automatic processing effects. American Journal of Psychology, 105, 181-199.

Bargh, J.A. (1996). Automaticity in social psychology. In E.T. Higgins \& A.W. Kruglanski (Eds.), Social psychology, Handbook of basic principles (pp. 169-183). New York: Guilford Press.

Bargh, J.A., Chaiken, S., Govender, R., \& Pratto, F. (1992). The generality of the attitude activation effect. Journal of Personality and Social Psychology, 62, 893-912. 
Bargh, J.A., Chaiken, S., Raymond, P., \& Hymes, C. (1996). The automatic evaluation effect: Unconditional automatic attitude activation with a pronunciation task. Journal of Experimental Social Psychology, 32, 104-128.

Bovens, N., \& Brysbaert, M. (1990). IBM PC/XT/AT and PS/2 Turbo Pascal timing with extended resolution. Behavior Research Methods, Instruments, and Computers, 22, 332-334.

Cacioppo, J.T., Berntson, G.G., \& Klein, G.G. (1992). What is an emotion? The role of somatovisceral afference with special emphasis on the somatovisceral "illusions"'. In M.S. Clark (Ed.), Emotion and Social Psychology. London: Sage.

Chaiken, S., \& Bargh, J.A. (1993). Occurrence versus modification of the automatic activation effect: Reply to Fazio. Journal of Personality and Social Psychology, 64, 759-765.

De Houwer, J., \& Hermans, D. (1994). Differences in the affective processing of words and pictures. Cognition and Emotion, 8, 1-20.

De Houwer, J., \& Hermans, D. (1999, June). Nine attempts to find affective priming of pronunciation responses: Effects of SOA, degradation, and language. Paper presented at the 7 th Tagung der Fachgruppe Sozialpsychologie, Kassel, Germany.

De Houwer, J., Hermans, D., \& Eelen, P. (1998a). Affective and identity priming with episodically associated stimuli. Cognition and Emotion, 12, 145-169.

De Houwer, J., Hermans, D., Rothermund, K., \& Wentura, D. (1998b). Affective priming of semantic categorization responses: A test of subordinate accounts of affective priming. Unpublished manuscript.

Draine, S.C., \& Greenwald, A.G. (1998). Replicable unconscious semantic priming. Journal of Experimental Psychology: General, 127, 286-303.

Fazio, R.H., Jackson, J.R., Dunton, B.C., \& Williams, C.J. (1995). Variability in automatic activation as an unobtrusive measure of racial attitudes: A bona fide pipeline? Journal of Personality and Social Psychology, 69, 1013-1027.

Fazio, R.H., Sanbonmatsu, D.M., Powell, M.C., \& Kardes, F.R. (1986). On the automatic activation of attitudes. Journal of Personality and Social Psychology, 50, 229-238.

Giner-Sorolla, R., Garcia, M.T., \& Bargh, J.A. (1994). The automatic evaluation of pictures. Unpublished manuscript, New York University, New York.

Glaser, J., \& Banaji, M.R. (1999). When fair is foul and foul is fair: Reverse priming in automatic evaluation. Journal of Personality and Social Psychology, 77, 669-687.

Glaser, W.R., \& Glaser, M.O. (1989). Context effects in Stroop-like word and picture processing. Journal of Experimental Psychology: General, 118, 13-42.

Greenwald, A.G., Klinger, M.R., \& Liu, T.J. (1989). Unconscious processing of dichoptically masked words. Memory and Cognition, 17, 35-47.

Greenwald, A.G., Klinger, M.R., \& Schuh, E.S. (1995). Activation by marginally perceptible ("subliminal") stimuli: Dissociation of unconscious from conscious cognition. Journal of Experimental Psychology: General, 124, 22-42.

Hermans, D. (1994). De Zelf-Beoordelings-Vragenlijst (ZBV) [The State-Trait Anxiety Inventory; Dutch adaptation], Gedragstherapie, 27, 145-148.

Hermans, D. (1996). Automatische stimulusevaluatie. Een experimentele analyse van de voorwaarden voor evaluatieve stimulusdiscriminatie aan de hand van het affectieve primingparadigma [Automatic stimulus evaluation. An experimental analysis of the preconditions for evaluative stimulus discrimination using an affective priming paradigm]. Unpublished doctoral dissertation, University of Leuven, Belgium.

Hermans, D. (1997). The Need to Evaluate Scale (NES). Unpublished authorised Dutch translation.

Hermans, D., Baeyens, F., \& Eelen, P. (1998a). Odours as affective processing context for word evaluation: A case of cross-modal affective priming. Cognition and Emotion, 12, 601-613.

Hermans, D., Crombez, G., \& Eelen, P. (2000). Automatic attitude activation and efficiency: The fourth horseman of automaticity. Psychologica Belgica, 40, 3-22. 
Hermans, D., \& De Houwer, J. (1994). Affective and subjective familiarity ratings of 740 Dutch words. Psychologica Belgica, 34, 115-139.

Hermans, D., De Houwer, J., \& Eelen, P. (1994). The affective priming effect: Automatic activation of evaluative information in memory. Cognition and Emotion, 8, 515-533.

Hermans, D., De Houwer, J., Smeesters, D., \& Van den Broeck, A. (1997, June). Affective priming with associatively unrelated primes and targets. Paper presented at the 6th Tagung der Fachgruppe Sozialpsychologie, Konstanz, Germany.

Hermans, D., \& Eelen, P. (1997). Automatische stimulusevaluatie: experimentele evidentie voor een oude hypothese [Automatic stimulus evaluation: experimental evidence for an old hypothesis]. Nederlands Tijdschrift voor de Psychologie en haar Grensgebieden, 52, 57-66.

Hermans, D., Van den Broeck, A., \& Eelen, P. (1998b). Affective priming using a colour-naming task: A test of an affective-motivational account of affective priming effects. Zeitschrift für Experimentelle Psychologie, 45, 136-148.

Holender, D. (1986). Semantic activation without conscious identification. Behavioural and Brain Sciences, 9, 1-66.

Jarvis, W.B.G., \& Petty, R.E. (1996). The need to evaluate. Journal of Personality and Social Psychology, 70, 172-194.

Kiger, J.I., \& Glass, A.L. (1983). The facilitation of lexical decisions by a prime occurring after the target. Memory \& Cognition, 11, 371-389.

Klauer, K.C. (1998). Affective priming. In W. Stroebe \& M. Hewstone (Eds.), European Review of Social Psychology (pp. 67-103). New York: Wiley.

Klauer, K.C., \& Musch, J. (1998). Affective priming: The puzzle of the naming task. Unpublished internal manuscript, University of Bonn, Germany.

Klauer, K.C., Rossnagel, C., \& Musch, J. (1995). Mechanismen affectiven Primings [Mechanisms of affective priming]. Unpublished internal manuscript, University of Bonn, Germany.

Klauer, K.C., Rossnagel, C., \& Musch, J. (1997). List-context effects in evaluative priming. Journal of Experimental Psychology: Learning, Memory, and Cognition, 23, 246-255.

Lazarus, R.S. (1991). Emotion and adaptation. New York: Oxford University Press.

LeDoux, J.E. (1989). Cognitive-emotional interactions in the brain. Cognition and Emotion, 3, 267289.

Martin, I., \& Levey, A.B. (1978). Evaluative conditioning. Advances in Behaviour Research and Therapy, 1, 57-102.

Musch, J., \& Klauer, K.C. (1997). Der Anteilseffekt beim affektiven Priming: Replikation und Bewertung einer theoretischen Erklärung. Zeitschrift Für Experimentelle Psychologie, 44, 266292.

Neely, J.H. (1977). Semantic priming and retrieval from lexical memory: Roles of inhibitionless spreading activation and limited-capacity attention. Journal of Experimental Psychology: General, 106, 226-254.

Öhman, A. (1987). The psychophysiology of emotion: an evolutionary-cognitive perspective. Advances in Psychophysiology, 2, 79-127.

Öhman, A. (1988). Preattentive processes in the generation of emotions. In V. Hamilton, G.H. Bower, $\&$ N. Frijda (Eds.), Cognitive perspectives on emotion and motivation. Dordrecht: Kluwer.

Orthony, A., Clore, G.L., \& Collins, A. (1988). The cognitive structure of emotions. London: Cambridge University Press.

Posner, M.I., \& Snyder, C.R.R. (1975). Facilitation and inhibition in the processing of signals. In P.M.A. Rabbitt \& S. Dornic (Eds.), Attention and performance: V (pp. 669-682). New York: Academic Press.

Powell, M.C., \& Fazio, R.H. (1984). Attitude accessibility as a function of repeated attitudinal expression. Personality and Social Psychology Bulletin, 10, 139-148.

Scherer, K.R. (1993). Neuroscience projections to current debates in emotion psychology. Cognition and Emotion, 7, 1-42. 
Spielberger, C.D., Gorsuch, R.L., Lushene, R., Vagg, P.R., \& Jacobs, G.A. (1983). Manual for the state-trait anxiety inventory. Palo Alto, CA: Consulting Psychologists Press.

Van der Ploeg, H.M., Defares, P.B., \& Spielberger, C.D. (1980). Handleiding bij de Zelf-Beoordelings Vragenlijst, $Z B V$ [Manual of the State-Trait Anxiety Inventory; Dutch adaptation]. Lisse: Swets \& Zeitlinger.

Wentura, D. (1998). Affectives Priming in der Wortentscheidungsaufgabe: Evidenz für postlexikalische Urteilstendenzen [Affective priming in the lexical decision task: Evidence for postlexical judgmental tendencies]. Sprache und Kognition, 17, 125-137.

Wentura, D. (1999). Activation and inhibition of affective information: Evidence for negative priming in the evaluation task. Cognition and Emotion, 13, 65-91.

Williams, J.N. (1996). Is automatic priming semantic? European Journal of Cognitive Psychology, 8 , 113-161.

Zajonc, R.B. (1980). Feeling and thinking. Preferences need no inferences. American Psychologist, $35,151-175$. 